\title{
Evidências de ciclicidade no ovário da fêmea muar
}

Andressa Guidugli Lindquist ${ }^{[a]}$, Suellen Miguez González ${ }^{[b]}$, Camila Bizarro da Silva ${ }^{[]]}$, Marcelo Marcondes Seneda ${ }^{[a]}$

\author{
[a] Universidade Estadual de Londrina (UEL), Londrina, PR, Brasil

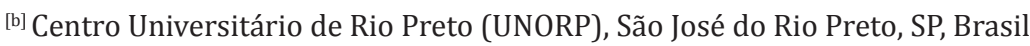

*Autor correspondente

e-mail: andressaguidugli@icloud.com

\section{Resumo}

As fêmeas muares apresentam características reprodutivas específicas, além de atualmente possuírem papel significativo como receptoras de embriões das espécies equina e asinina. Sugere-se que as mulas demonstram atividade ovariana pela dinâmica folicular e evidência de processos de ovulação, no qual um oócito é eliminado, ocorrendo, assim, a formação do corpo lúteo. Novos conhecimentos sobre a dinâmica reprodutiva da mula poderão viabilizar sua eficiência reprodutiva como receptora de embrião. Assim, objetivou-se nesse trabalho investigar as particularidades reprodutivas das fêmeas muares, tais como a incidência de folículos, corpos lúteos e oócitos nos ovários. Foram utilizados ovários muares ( $\mathrm{n}=14$ ) obtidos em abatedouro local, transportados ao laboratório em recipiente térmico (26 ㄷ) e submetidos à dissecação da túnica albugínea e tecidos conectores. Em seguida, estes foram pesados e avaliados quanto a presença de folículos antrais e/ ou corpos lúteos. Os folículos aspirados ( $\mathrm{n}=7$ ) obtinham diâmetro entre 4 a $10 \mathrm{~mm}$, e para tanto utilizou-se agulha 40x12 mm (18G 1 1⁄2) conectada à seringa de 20 mL, contendo solução heparinizada. Sob lupa estéreomicroscópica, avaliou-se os oócitos quanto à qualidade do ooplasma e características das células do cumulus oophorus (grau I, II, III e desnudo). 0 peso médio dos ovários foi de 7,79g, sendo que os que apresentaram folículos antrais obtiveram maior peso (26,3g) em comparação com aqueles que obtiveram apenas corpos lúteos (2,24 - 9,17g). Constatou-se incidência de corpos lúteos em 64\% (9/14) dos ovários de mulas, enquanto $21 \%$ (3/14) possuiam folículos antrais. Foram recuperados seis oócitos dos sete folículos aspirados, resultando na taxa de recuperação de 85,7 \%. Quanto à avaliação dos oócitos, três destes foram classificados como Grau I e o restante em Grau II. Portanto, os indícios de ciclicidade evidenciados neste trabalho poderam contribuir para o entendimento da fisiologia reprodutiva dessas fêmeas.

Palavras-chave: Mula. Folículos. Corpo lúteo. 